\title{
Reliable Estimate and Software Development/Jordanian Environment
}

\author{
Mohammad Mahmoud Tarawneh \\ Balqa Applied University \\ Karak University Collage
}

\author{
Sattam Rakan Allahawiah \\ Balqa Applied University \\ Karak University Collage
}

\begin{abstract}
This paper aims to shed light on one of the important factors affecting the software products industry in the Jordanian Environment An estimate the cost effectiveness and the effect on the development of software products industry, where this factor plays an important role in measuring the success of managers of software projects in the management of such projects, the study concluded that this loft to important findings and recommendations, perhaps software project managers in Jordan that take into account the ill-received by the.
\end{abstract}

\section{Keywords}

Software product, reliable estimate, Software Size Estimation, Cost and Schedule Estimation, Cost Estimation and Budgeting

\section{INTRODUCTION}

The software product cost estimation is one of the most important factors that could affect the process of assessing the success of a software product (Eldabi et al., 2003; Liu et al., 2003). There are many reasons that make the process of estimating the cost of the obscure and difficult software product such as: technological obsolescence due to the growing sophistication in technology so that the process of bringing new technology old place although the old town is still operating, change and uncertainty in business requirements, On the basis of the above-mentioned difficult to have a cost reliable estimate of these systems ((Farbey et al., 1993, 1999)).

Therefore, for the development of software product reflects a realistic appreciation for this product should be on the software project managers to use all they possessed of the knowledge and experience of the precedent and that there should be cooperation by the group as a whole in order to put an estimate reflects the effort and cost required (Extreme chaos, 2001).

The budget and forecasting software product costs are an important factor in the success or failure of the software product, where the process of predicting software product costs are uncertain and difficult due to several reasons such as requirements ambiguity and change, replacement of technology (Red, 1999). The size of the project, lack of clarity of vision and planning correctly and resistance change from the old system (Verner et al, 2006).

Increased spending on software products in Jordan and most of the world countries is increasing, especially with the directions toward the computerization of all paper-based transactions so that all digital transactions, therefore, the question of the evaluation of projects and software products is the concern of all decision makers in Jordan. Now a large part of the expenditure of the organizations in the information technology sector, Software, directly or indirectly, the decision makers want to make sure that these investments justified and their return be Cost-effective (Farbey et al., 1993; 1999).

This ongoing interest in investment in this sector need to convincing justification for the decision makers in those organizations Midwestern is one of the greatest challenges of the Community Software Engineering (Dabrowska and Cornford 2001; Irani et al. 2002).

The aim of this research to find out the impact of the appreciation of the extent of the success of reliable estimate software projects in the Jordanian environment and the use of the exploratory research methodology through the study of documents available desktop software companies in Jordan the previous projects as well as the identification of distributed to 120 questionnaires for software projects manager as well as a personal interview with 20 mangers

\section{RELIABLE ESTIMATES}

According to the Extreme chaos report (2001), reliable estimates were replaced in the ninth position in terms of importance for the success of a software product. The report stresses the importance of managers using their collective knowledge and experience in reaching reliable and realistic estimates in the various project phases. According to many authors (Farbey et; al., 1993; 1999; Eldabi et; al, 2003, Red, 1999, Verner et; al, 2006) estimating project cost is one the most difficult estimation tasks. This is due to many reason, e. g. technological and requirements changes, schedule changes, differing customer needs and project size. Adaptive partner (2006) adds to these, ambiguous requirements, resistance to change, and lack of planning and unclear objectives. Methods used to carry out cost estimation for software projects play an important role in the precision of cost estimated (Lionel and Katrina, 1999). The reliable estimation includes:

\section{Software Size Estimation}

Cost and Schedule Estimation

Cost Estimation and Budgeting

\subsection{Software Size Estimation}

There is a lot of step should be estimated for software project The key step is concentrated in estimating the size of the software projects to be built or developed. This has direct effect on the cost and schedule estimates. One of the most difficult things in the assessment process is implemented in a bad way and wrong, leading to an increase in the cost of a software product and beyond what had previously been rescheduled.

Estimate the size of a software product depends essentially on two matters: - lines of code and function points. There is no clear methodology or a binding law to estimate the number of lines of code, but an estimated compared to previous similar 
products in the past. The function point analysis does not require knowledge of the basis of the instructions of the program code but is based mainly to understand business functions. The function points there are many factors that affect the input, Outputs, inquiries, master files, and interfaces with other programs. The function of the amendment is done on the number of raw score technical complexity and environmental factors in order to reach a definitive and save estimate. In most cases the function point on access to reliable estimates properly and is independent of the Programming. Currently, there are commercial programs and tools to assess and analyze the function point of support Dreger (1989) and Jones (1991).

\subsection{Cost and Schedule Estimation}

There are two approaches to estimate the costs and deadlines of the software product a methodology are top-down and bottom-up. The methodology from top-down and bottom-up trying to deal with the estimation of the total cost of the project scheduling software product, usually using automated programs to estimate the costs and scheduling. This process used in how to turn the volume measure effort (I e: months and the duration of the project in terms of the number of days, weeks and months. Despite the existence of many algorithms and rules of thumb, to adjust the estimates organizational productivity and other factors affecting. Then the size of the estimates used for the specific efforts of tasks and activities and identifies indicators of development agenda (Jones, 1996). While the bottom-up approach that begins with the estimation of staff requirements and clients and start tabulated starting from the lowest of tasks and then assembled at the higher levels of the estimates of the Tasks and milestones (Larson and Fasto, 1989).

In order to reach a good result and satisfactory, many companies use two approaches in an iterative process. Where we use the method from the top -down to identify and characterize the guidelines of the project as a whole. While we use the top-bottom approach to set a timetable/schedule and cost estimates in a detailed and accurate within the frameworks of the border within the constraints established by the top-down approach.

But this method would need a lot of appreciation before turning to satisfactory Estimates. There are many commercial software tools available to assist the Action Team on the outcome of the work of the Estimates and scheduling regular working conditions. In addition to the capacity to provide the cost of the agenda through trade-offs between projects where the table can be shortened by adding more staff. According to (Boehm, 1981) effective and practical 25\% of the efforts to limit the table did not succeed. A good scheduling full of challenges and risks that must be reasonable and achievable. And that you have the project team is committed to. The best way to get the commitment of the project team is that each task of assessing the appropriate number of individuals or groups responsible for the completed schedule estimated. Often in large projects main streams are divided into smaller agenda thus, in which the main activities equipped with detailed schedules, especially to the lower tier of the Action Team. Gantt chart some of the most common ways to use the schedule information to display a chart horizontally with time scale as shown in (Figure 1). Gantt chart gives many advantages and as well as the easy-to-understand construction and revision, but did not indicate the interdependence between the various tasks. One of the best ways used to illustrate the mutual relations between the different tasks is the agenda of the network PERT and CPM (critical path method) It is one of the most common tools in the Timetable are the networks because it shows the extent of the interdependence between the tasks. A sample schedule network is shown in (Figure 2).

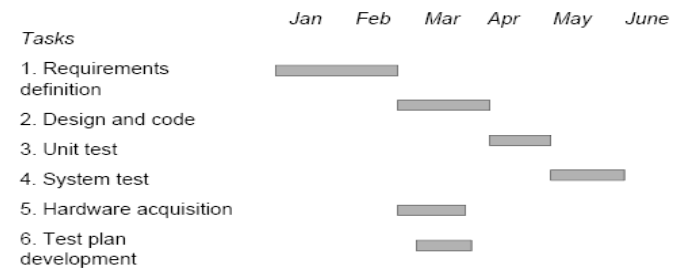

Fig 1. Sample Gantt Chart (jurison, 1999)

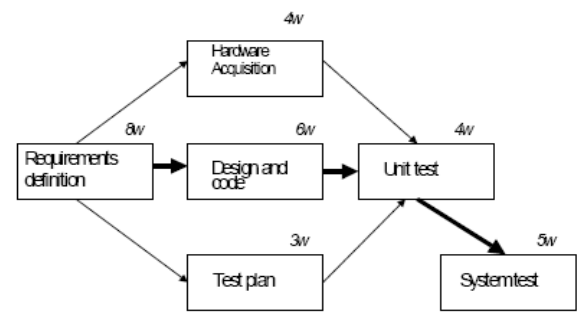

$w=$ drationinueds

Fig 2. Sample Schedule Network (jurison, 1999)

The scheduling of networks has many advantages, the most important of which is used in the definition of the critical path of the project. Through identified a range of activities on the course of the project take longer time (shown as the bold line in Figure 2.9). In fact, identifying the critical path be determines when the project will be finish. Important to identify the critical path of the project management software requires attention and be cautious because any timetable for an error in the Tasks lead to an error in the end date of the project is therefore to identify the critical path of important things and any error which is a grave mistake (see table below), all the project management software include tools and means of establishing such Gantt and schedule networks (jurison, 1999) .

\subsection{Cost Estimation and Budgeting}

According to Jones $(1991,1996)$ cost estimation and budgeting are important and challenging estimating task, costs driven for software projects mainly is costs of staff As well as the use of automated assessment tools or using the rules of the existing historic data in the company itself can be used to estimate the number of working hours of staff, which is the result of the estimates of the size of the project, with the help of such tools here, these estimates should be adjusted to the capabilities of the team work skills and experience. This is done through a detailed assessment of all activities, heard a work report to include project management and support functions such as quality assurance. Larson and fasto (1989) obtain Estimate all direct and indirect costs in the software project such as labor costs, this is done by multiplying the number of working hours of staff in each of the items of the project including the tasks entrusted to experts, travel and any tangible matters. Estimate the total budget for the project is through the collection of direct and indirect costs, as well as must take into account the unexpected crises management problems that may occur during the implementation of that plan. From the useful and which is considered a tool in the hands of project managers is the cumulative cost curve 
because it represents the budget GRAPHICALLY as a function of time according to the schedules as shown in (Figure 3)

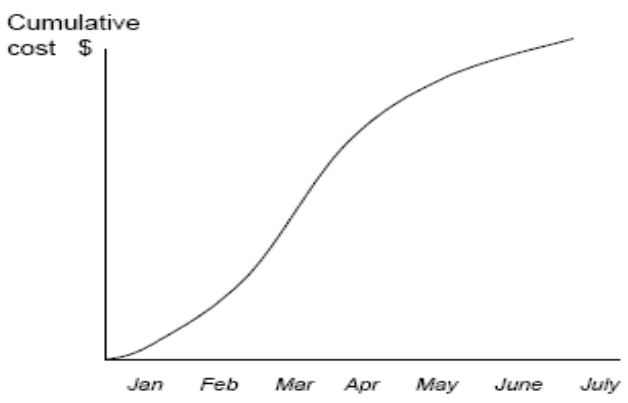

Fig 3 . Cumulative Cost Curve (jurison, 1999)

\section{DATA ANALYSIS}

Table 1. Means and standard deviations of subjects' perceptions of Reliable Estimation factor

\begin{tabular}{|c|c|c|c|c|c|c|c|c|c|}
\hline \multirow[t]{2}{*}{ No } & \multirow[t]{2}{*}{ Symptoms } & \multicolumn{3}{|c|}{ Severity degree } & \multicolumn{3}{|c|}{ Frequency degree } & \multirow[t]{2}{*}{ T.Value } & \multirow[t]{2}{*}{ Sig } \\
\hline & & Mean & Std & Severity & Mean & Std & Severity & & \\
\hline 1 & $\begin{array}{l}\text { Project plan or budget is ideal ,pessimistic } \\
\text { or mixed }\end{array}$ & 3.72 & 0.94 & high & 3.65 & 0.95 & high & $22.84 *$ & 0.00 \\
\hline 2 & $\begin{array}{l}\text { Same problems of the project frequent, but } \\
\text { it seems that we don't stop to learn and fix } \\
\text { the wrong }\end{array}$ & 3.68 & 1.01 & high & 3.59 & 1.02 & high & $22.81 *$ & 0.00 \\
\hline 3 & $\begin{array}{l}\text { Projects budget is more than what is } \\
\text { required in terms of work hours / costs }\end{array}$ & 3.66 & 0.92 & high & 3.60 & 0.94 & high & $19.43^{*}$ & 0.00 \\
\hline 4 & $\begin{array}{l}\text { Resources manager work with many } \\
\text { principals which means that non of them is } \\
\text { totally satisfy }\end{array}$ & 3.61 & 0.94 & high & 3.56 & 1.01 & high & $18.08^{*}$ & 0.00 \\
\hline 5 & Extra costs are added to the project & 3.59 & 0.96 & high & 3.55 & 0.99 & high & $17.04 *$ & 0.00 \\
\hline 6 & $\begin{array}{l}\text { Communication, coordination, and reports } \\
\text { about the project's situation take much time } \\
\text { and big resources }\end{array}$ & 3.57 & 0.98 & high & 3.51 & 0,97 & high & $15.54 *$ & 0.00 \\
\hline 7 & $\begin{array}{l}\text { Project plan is developing and increasing by } \\
\text { increasing the project's size }\end{array}$ & 3.55 & 1.01 & high & 3.50 & 0.98 & high & $14.44^{*}$ & 0.00 \\
\hline 8 & $\begin{array}{l}\text { Often the project is divided according to the } \\
\text { size }\end{array}$ & 3.53 & 0.97 & high & 3.48 & 1.02 & Middle & $12.99 *$ & 0.00 \\
\hline 9 & $\begin{array}{l}\text { Costs, resources, and benefits for important } \\
\text { project are estimated in pessimistic way } \\
\text { which may lead to cancel it }\end{array}$ & 3.51 & 0.96 & high & 3.47 & 1.03 & Middle & $12.81^{*}$ & 0.00 \\
\hline 10 & $\begin{array}{l}\text { We waste time and resources during } \\
\text { implementation stage because of ineffective } \\
\text { planning }\end{array}$ & 3.49 & 0.93 & Middle & 3.40 & 1.02 & Middle & $12.70^{*}$ & 0.00 \\
\hline 11 & $\begin{array}{l}\text { Playing with project's plan and cost } \\
\text { estimation losing them their reliability }\end{array}$ & 3.47 & 1.00 & Middle & 3.39 & 0.97 & Middle & $11.70^{*}$ & 0.00 \\
\hline 12 & $\begin{array}{l}\text { We give extra time and resources for } \\
\text { projects planning. }\end{array}$ & 3.30 & 1.02 & Middle & 3.21 & 1.05 & Middle & 10.94 & 0.00 \\
\hline & Total mean & 3.56 & 0.63 & high & 3.49 & 0.66 & Middle & 21.47 & 0.00 \\
\hline
\end{tabular}


Table (2) Mean and percentages of reliable estimations

\begin{tabular}{|c|c|c|c|c|}
\hline No & Item & Mean & Percentage & Rank \\
\hline 1 & $\begin{array}{l}\text { Project manager failure in estimating costs affect usability of } \\
\text { the system }\end{array}$ & 11.94 & $59.70 \%$ & 1 \\
\hline 2 & $\begin{array}{l}\text { If the system has been implemented very late, it becomes } \\
\text { invalid }\end{array}$ & 11.90 & $59.50 \%$ & 2 \\
\hline 3 & $\begin{array}{l}\text { Lack of experience of managers in achieving projects in } \\
\text { Jordan }\end{array}$ & 11.35 & $56.75 \%$ & 3 \\
\hline
\end{tabular}

The arrangement of reliable estimation items as following: Project manager failure in estimating costs affect usability of the system $(59.70 \%)$; if the system has been implemented very late, it becomes invalid (59.50\%); and lack of experience of managers in achieving projects in Jordan. The arrangement of reliable estimation items as following: Project manager failure in estimating costs affect usability of the system $(59.70 \%)$; if the system has been implemented very late, it becomes invalid $(59.50 \%)$; and lack of experience of managers in achieving projects in Jordan.

\section{RESULT DISCUSSION:}

Reliable estimate is considered one of the basics of ensuring the success of the software project, through this study indicate to us as researchers, there is a lack of experience and the number of managers of software projects, which have the ability to use modern tools and means in the assessment process rather than rely on previous experience and expertise in the assessment process for the project cost and time softwhere the number of workers in the delivery of a software product as well as a weakness in the process of estimating the revenue with cost this entails many risks because each software product for different working conditions and environment through field study shows us that there is a lot of software projects that exceeded the estimated budget of the high cost and time although the Jordanian environment is one of the promising markets in software industry.

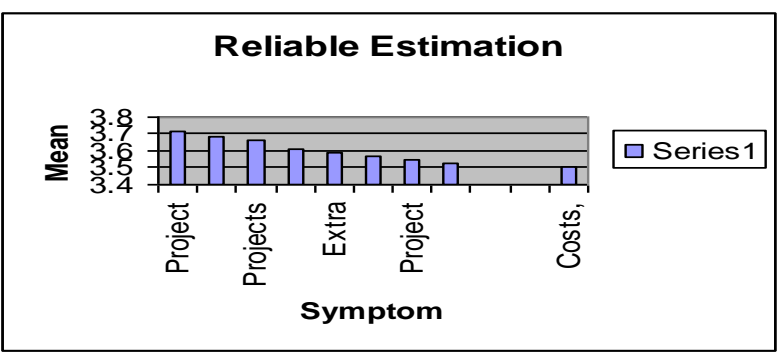

Figure 4. Reliable Estimation according to Questionnaire

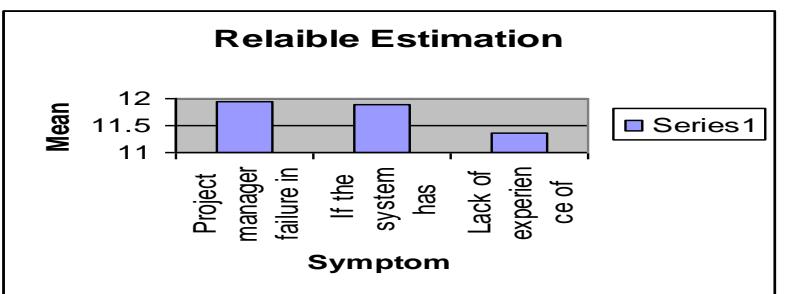

Figure 5. Reliable Estimation according to interview

\section{RECOMMENDATION:}

The software project managers estimate the costs of the project through a combination of factors (programs, data, technical information) they must project cost management through a series of operations to ensure the completion of the project within the budget set out this is done through a combination of factors:

(1) Recourses Planning:

By assessing and identifying the needs of the software project of the human and material resources required to complete the project, and this requires the division of labor and access to previous information for previous periods to determine the framework and limits of the project accurately described the total resource requirements, whether material or human, to identify appropriate regulatory policies to deal with the software project.

(2) Costs Estimate :

Here we must estimate the size of the cost required to complete the project, this requires the Project Manager software determine the prices of resources and needs some information on costs in previous periods.

(3) Budget Determine:

The manager of a software project to identify sources of expenditure, which accompany every activity of the project, and the attic to ensure that an assessment of the cost structure of the division of labor between the members of the team and the timetable for the expected completion of the project.

(4) Costs Control:

The Director of the software project monitoring the changes that may occur in the project budget through performance reports and requests for amendment to the costs that may occur during the completion of the project.

The project Quality Management:

To ensure the implementation of the operations and performance of the same quality level, which was contracted or agreed upon three basic operations?

Quality Planning: The identification of appropriate quality standards and a mechanism to achieve software-project these standards through reference to quality policies, procedures, and methods of performance compared with the cost-benefit analysis.

Quality assurance: Attention should focus on the evaluation of the performance of the software project periodically to make sure they comply with the specifications and features and control the expected results in order to improve the quality of a software product.

Quality control: Action to deal with the deviations that might arise during the implementation of the software project, and through quality control can improve the quality of the software product meets the needs of the final customer. 
Project Human resources management:

The process of optimizing the use of the human resources involved in the project management software are as follows::

The organizational planning: here must be to identify the major responsibilities and roles in the project and to prepare appropriate reports for each role and the responsibilities of the attic.

The human resource management, here is the appointment of personnel involved in the implementation of the software project.

The composition of the working group this is done through the formation of appropriate team of the nature of the work and the appropriate distribution of roles among the members of the Panel.

\section{REFERENCES}

[1] Boehm, B. 1991. Software Risk Management: Principles and Practices. IEEE Software, Vol 8[1],32-41.

[2] Dabrowska, E. and Cornford, T. (2001) Evaluation and Telehealth - an Interpretative Study. Proceedings of the Thirty-Fourth Annual Hawaii International Conference on System Sciences (HICSS)-34. January 2001, Maui, Hawaii, Computer Society Press of the IEEE, Piscataway, N.J., (CD-ROM).

[3] Dreger, B.J. (1989)," Function Point Analysis", Englewood Cliffs, NJ: Prentice Hall.

[4] Eldabi, T., Paul, R. J. and Sbeih, H. (2003) Operational Use Evaluation/Post Implementation Evaluation of IT, Proceedings of UKAIS, 9-11 April, Editors: Levy, M., Martin, A. and Schweighart, C., Warwick University, (CD-ROM).

[5] Farbey, B., Land, F. and Targett, D. (1993) How to assess your IT investment: a study of methods and practice, Butterworth-Heinemann Ltd., London.
[6] Farbey, B., Land, F. and Targett, D. (1999) Moving IS Evaluation Forward: Learning Themes and Research Issues, Journal of Strategic Information Systems, Vol.8, pp $189-207$

[7] http://www.adaptivepartners.com/projfailb.htm; Accessed at 30/1/2018 on 10:25 pm.

[8] http://www.standishgroup.com, Accessed at 1/2/2018.

[9] Irani, Z. (2002) Information Systems Evaluation: Navigating Through the Problem Domain, Internationa Journal of Information and Management, Vol. 40, No. 5, pp. 11-24.

[10] Jones, C, (1991), "Applied Software Measurement: Assuring Productivity and Quality", New York: McGraw-Hill.

[11] Jones, C. (1996) "Software Estimating Rules of Thumb," Computer, March, pp. $116-118$.

[12] Jurison, J. (1999) "Software project Management: A Manager's View," Communications of AIS, Vol. 2, Article $\quad 17, \quad$ September 1999. http://cais.isworld.org./articles/2-17/

[13] Larson, C.E. and Fasto, F.M.J. (1989) Teamwork, Newbury Park, CA:Sage Publications.

[14] Lionel C. Briand and Katrina D. Maxwell, An Assessment and Comparison of Common Software Cost Estimation Techniques, ACM , 1999.

[15] Lui, K. (2003). Organizational Development Class Notes. Menomonie.

[16] Verner, J., Evanco, W., Cerpa, N, (2006) State of the Practice: An exploratory analysis of schedule estimation and software project success prediction, information and software technology ,p 181-193 